\title{
A sina de Odisseu e o que o nome ensina
}

\section{Resumo}

Quero explorar aqui um expediente fundamental da Odisseia: o jogo em grego entre Odusseús e o verbo odússomai. Trabalhando com essa etimologia fantasiosa, mas eloquente, Homero parece nos forçar a ver em "Odisseu" um nome tão transparente quanto o de outros personagens da narrativa, e chamar nossa atenção para implicações trazidas por esse jogo, especialmente a ligação com seu desaparecimento e a cólera vinda dos deuses.

Palavras-chave: Odisseu; Odisseia; Nome.

\begin{abstract}
In this article, I focus on one specific element of the Odyssey: the pun between Odusseús and the verb odússomai. By playing with this false and resounding etymology, Homer seems to force us to see Odysseus' name as one as transparent as other characters' names in the poem, and call atention to the implications this pun brings about, especially its connections with his fate as someone who desappears and is the object of the anger that comes from the gods.
\end{abstract}

Keywords: Odysseus; Odyssey; Name. 
$\mathrm{U}$

ma das particularidades da Odisseia que mais chamam a atenção dos estudiosos é a omissão do nome do herói na abertura do poema, em franca oposição ao que vemos na Ilíada, onde Aquiles é mencionado já na primeira linha: "O varão me evoca, Musa, multiforme, que muitíssimo..." (Od. 1, 1) / "A fúria agora canta, deusa, do Pelida Aquiles..." (Il.1, 1). ${ }^{1}$ De fato, apenas no verso 21 ouvimos Homero falar "Odisseu”. Não se trata, naturalmente, da criação de um suspense: todos que ouvimos e lemos essa narrativa, mesmo que pela primeira vez, sabemos de quem se trata. O acréscimo do adjetivo "multiforme" (polútropos), além do mais, especifica de maneira inequívoca o herói cuja característica principal é a versatilidade. A omissão, no entanto, parece ter uma função clara no contexto mais amplo do poema: anunciar um motivo seu fundamental, que Irene De Jong chama de "supressão do nome" e está ligado, na realidade, à questão da identidade $(2001,7)$. Em outras palavras, o fato de Odisseu ser tardiamente nomeado - e, mais do que isso, virar o foco da ação apenas no Canto 5 - parece ser um recurso para indicar os problemas de identificação por que passa ao longo da história, desde seu desaparecimento até a progressiva reconquista de sua posição em Ítaca.

Visto em seus detalhes, esse motivo da supressão do nome - e, por extensão, do "desaparecimento" - parece se desdobrar em dois movimentos distintos: de um lado, temos um Odisseu que fica sem nome (e sem renome) de modo involuntário, à sua revelia; e, de outro, um herói que procura voluntariamente essa omissão, que a emprega como estratégia fundamental exatamente para que assim se afirme a sua identidade. Esses dois movimentos mereceriam artigos à parte, e por isso os deixo de lado aqui. Dentro desse campo da nomeação, prefiro me deter por ora neste que é um outro expediente fundamental da Odisseia: a associação em grego de

1 Todas as traduções, do grego e da literatura secundária, são de minha autoria.

Filosofia e Educação [RFE] - Volume 9, Número 1 - Campinas, SP

Fevereiro-Maio de 2017 - ISSN 1984-9605 - p. 25-44 
Odusseús e o verbo odússomai. Por meio de alguns jogos de palavra, Homero - como Platão no Crátilo, onde brinca com o sentido dos nomes próprios - parece querer que vejamos em "Odisseu" um nome tão transparente quanto $\mathrm{o}$ de outros personagens da narrativa, com as respectivas implicações para seu destino, e uma possível ligação entre seu desaparecimento e a cólera divina.

Por conta do sentido elástico do verbo odússomai - e em função da presença da voz média em grego (além da ativa e passiva) -, os estudiosos não estão totalmente de acordo em relação à ideia que se quer transmitir ao nome do herói. Jenny Clay, em seu livro sobre a Odisseia, define assim o verbo: “significa 'ter sentimentos hostis ou inimizade em relação a alguém’. O termo abarca uma gama de sentidos, incluindo 'ficar irritado', 'odiar alguém', 'chatear', 'perturbar', 'ofender'” (1983, 59-60). Clay mostra que na Ilíada o verbo aparece quatro vezes, tendo como sujeito Zeus ou os deuses $(I l .6,138, I l .8,37=468$ e $I l .18,292)$, sempre designando a cólera divina. Na Odisseia, o uso é idêntico, sendo que o alvo da ira dos deuses é sempre Odisseu (1983, 62-64). A única exceção é o debatido passo do Canto 19, quando temos a seguinte fala de Autólico, avó do herói:

Genro meu e filha minha, dai o nome que eu disser:

já que chego aqui com muitos me dirigindo o ódio seu (odussámenos)

- mulheres e homens, ao longo do chão multialimentante -,

Odisseu (Oduseús), por isso, seja o nome a chamá-lo (...).

(Od. 19, 406-409)

Na realidade, por causa da voz média, o particípio odussámenos pode ser tomado nessa passagem, literalmente, como "tendo ódio", "agastando-

Filosofia e Educação [RFE] - Volume 9, Número 1 - Campinas, SP

Fevereiro-Maio de 2017 - ISSN 1984-9605 - p. 25-44 
se" (por muitos/com muitos) - como acontece em todas as outras ocorrências do verbo, quando devemos optar por uma forma ativa em português -, ou ainda, se lido passivamente, como "sendo odiado", "sendo alvo do ódio" (por muitos/de muitos; na minha tradução mais livre, para recriar o jogo, "com muitos me dirigindo o ódio seu"). O esclarecimento desse ponto gramatical é importante para decidirmos se "Odisseu” é tomado aí como "o que tem ódio" ou, ao contrário, "o que é alvo do ódio".

Para a helenista norte-americana, deve-se preservar o delicado balanço entre esses dois sentidos, de modo a vermos o herói, de modo geral, como o “homem da cólera". Essa posição, na realidade, não é nova: o comentário de Merry e Riddell, do final do século XIX, já indicava essa ambivalência (1876, v. 1, 8), embora ela não fosse corrente entre os comentadores mais antigos, que, segundo John Peradotto, optavam por ver aí um sentido exclusivamente passivo (misetheís, "detestado", como propõe o escólio a Od. 19, 407), ainda que destoante do emprego mais comum do verbo ${ }^{2}$. O próprio Peradotto, contudo, veio a se tornar talvez o principal propositor da indeterminação, como mostra o título de seu importante livro, Homem na voz média: nome e narrativa na Odisseia, no qual faz uma excelente discussão do problema (1990, 129-142).

Para tornar a questão ainda mais intrincada, deve-se dizer que, para alguns, a noção de "dor" também está implicada em odússomai, por conta de uma possível associação etimológica com o substantivo odúne, "tristeza", o que faria com que pudéssemos entender o verbo como "semear dor para alguém". O principal defensor dessa leitura foi George Dimock, que vê Odisseu como o herói que primeiro experimenta a dor para, depois, infligi-la

2 Vincenzo Di Benedetto (2010, 1019), explorando a terminação -eus, como em hiereús, "sacerdote", entende que Autólico inverte no Canto 19 o uso mais comum no poema e que o valor do verbo é ativo, “odiando". D. Monro $(1901,169)$ também não admite sentido passivo.

Filosofia e Educação [RFE] - Volume 9, Número 1 - Campinas, SP

Fevereiro-Maio de 2017 - ISSN 1984-9605 - p. 25-44 
a seus inimigos. A conexão seria explorada pelo próprio herói, ao jogar com as formas dativa (odúneisin, Od. 17, 567) e genitiva (odunáon, Od. 19, 117) de odúne $(1989,4,13$ e 246-263)

Diante desses elementos, que posição podemos adotar? Parece-me que no original as ideias de "cólera", "ira", "ódio" têm preponderância sobre as de "dor", "sofrimento", e que a interpretação mais antiga - que fica com o valor passivo para a passagem do Canto 19 - deve ser ainda mantida, fazendo com que tomemos "Odisseu" como "o odiado". Essa é a visão esposada, mais recentemente, por Irene De Jong em seu comentário (2001, 477), e deve-se dizer que mesmo Clay e Peradotto, que preferem manter a “abertura” semântica, propõem ambos traduções iniciais em que Odisseu surge como "alvo do ódio". No contexto, essa ideia aparentemente se ajusta melhor ao comportamento ladino de Autólico - que despertaria reações desfavoráveis por superar a todos "em furtividade e jura" (kleptosúnei th" hórkoi te, Od. 19, 396) -, e marcaria uma contraposição, pela carga negativa, ao nome aparentemente benévolo sugerido por Euricleia, "Poliareto" (poluáretos), isto é, "Aquele por quem muito se orou"/“Multirogado" (Od. 19, 404). Além disso, o entendimento de que "Odisseu" é "o detestado" vem confirmado por um fragmento atribuído a Sófocles, em que o próprio herói justifica a origem de seu nome, possivelmente numa alusão à Odisseia: "Corretamente (orthôs) tenho pelos males o apelido de Odisseu:/ pois recebi de muitos - hostis a mim - o ódio seu (odúsanto)" (Fr. 965 Pearson $=965$ Radt $)^{4}$.

3 Ele mesmo, no entanto, dá mais ênfase à ideia de ódio e hostilidade contida no verbo (ver, por exemplo, p. 73-74). W. Stanford (1947, v. 1, 215, e v. 2, 328 e 332-333) também trabalha com esse campo semântico em seu comentário, vendo Odisseu como o "filho da dor". Em um artigo posterior, no entanto (1952, 209-213), Stanford preferiu destacar o valor passivo de odússesthai e ver o herói como aquele "fadado ao ódio".

4 A tradução foi adaptada para recriar em português o jogo original. Literalmente temos: "Pois muitos me odiaram, hostis a mim". O fragmento é citado por J. Clay (1983, 60, nota 12). Lembre-se da conhecida explicação dada ao nome "Helena" ("arrebatadora") no Agamênon de Ésquilo (v. 681-698).

Filosofia e Educação [RFE] - Volume 9, Número 1 - Campinas, SP

Fevereiro-Maio de 2017 - ISSN 1984-9605 - p. 25-44 
Os argumentos mais fortes, na realidade, vêm da própria Odisseia: em todas as demais ocorrências do jogo entre Odusseús e odússomai, fica claro que o movimento é no sentido de apresentar Odisseu como alvo do ódio divino, e não como alguém que, inversamente, sente ódio. Primeiramente, é Atena quem faz o trocadilho, ao se dirigir a Zeus (a mudança em português para a terceira pessoa do singular - em lugar da segunda, como em grego foi feita com a intenção de se recriar o jogo): “Acaso Odisseu/ junto às naus argivas não te agradou com sacrifícios,/ na vasta Troia? Por que lhe vota Zeus o ódio seu (odúsao)?” (Od. 1, 60-62). Depois é Ino, no Canto 5, que destaca a conexão entre irritação divina e sofrimento humano, ao querer saber por que Posídon lhe deu/ o ódio seu (odúsato) (Od. 5,339-40). Finalmente, temos duas ocorrências em que o próprio Odisseu explora esse jogo verbal, num monólogo do Canto 5 ("me tem dado o ódio seu o Tremeterra", v. 423) e no momento em que mistura verdades e mentiras para Penélope, no Canto 19 ("pois lhe deram o ódio seu/ Zeus mais o Sol”, v. 275-276).

Em todos esses passos odússomai tem, de fato, um sentido mais ativo para nós - "agastar-se" -, mas é precisamente o fato de Odisseu ser o alvo sempre desse agastamento que parece permitir que, na formulação de Autólico do Canto 19, o verbo possa ser lido passivamente - não como "agastando-se", mas sim como "sendo alvo do agastamento de". Sendo assim, a nomeação do bebê Odisseu tem valor profético, antecipando a perseguição divina que sofrerá: os trocadilhos com que vamos nos deparando ao longo da narrativa - pelos quais "Odisseu" vai sendo equacionado com o "ódio seu" (dos deuses) - recebem sua explicação na digressão sobre seu nascimento, quando foi denominado "o odiado". Desse modo fica estabelecida uma coerência interna, que seria perturbada se admitíssemos a possibilidade de "Odisseu” ser "o que tem ódio" - ideia que 
o poema em momento algum parece destacar e que, de certa maneira, comprometeria a frieza do herói "multiastuto", aproximando-o da tradicional figura do encolerizado Aquiles.

Se fica então sugerido que Odisseu é o odiado, se esse nome resume o próprio homem e seu destino (nomen est omen, já dizia outro jogo), devemos nos perguntar que ódio é esse, como Homero o apresenta e quais as consequências para a nossa compreensão do comportamento do herói. Vemos, nos trocadilhos, as referências a Zeus, Posídon e o Sol como portadores dessa cólera, nos Cantos 1, 5 e 19, mas é preciso explorar ainda outras menções fundamentais, principalmente na parte inicial do poema. A de Posídon é certamente a mais evidente, porque se apresenta como fator decisivo na volta retardada de Odisseu; além do mais, ela já nos é apresentada no prólogo, pela boca do narrador e de Zeus, respectivamente (v. 11-21 e 68-79). Sabemos que, apesar de sua importância para a história, essa cólera só se manifestará de fato uma única vez, no Canto 5, depois de Posídon descobrir que Odisseu deixou a ilha de Calipso (v. 282-450).

Ao ver o herói navegando sobre o mar, o deus se encoleriza (ekhósato, v. 284) e desencadeia uma tempestade que faz com que subitamente "a noite surja do céu" (v. 294). Odisseu responsabiliza Zeus pela tormenta (v. 303304) mas, a partir da intervenção de Ino, que associa explicitamente o sofrimento do herói ao "treme-terra Posídon" (v. 339) - no já mencionado passo do trocadilho, onde fala do deus como também alguém que "se enfurece" (meneaínon, v. 341) -, a partir daí, também Odisseu passa a se referir especificamente a essa divindade (v. 423 e 446), embora ainda pareça hesitante nos versos 356-357, em que imagina a ação ardilosa de "um dos imortais" por detrás das palavras de Ino. Essa perseguição a Odisseu por parte de uma divindade indeterminada é indicada por Telêmaco no Canto 1: o filho recorre ao mesmo campo semântico quando diz a Mentes-Atena que, 
ao invés de um destino glorioso para o pai, "quiseram de outro modo - com astúcias más - os deuses (kaká metióontes theoi)" (Od.1, 234). Mas a afirmação mais contundente da percepção de uma ira divina - sem um rosto específico - voltada contra o herói vem no Canto 10 (v. 72-75), quando Éolo diz a Odisseu, ao vê-lo de volta, depois da ajuda recebida, que ele é destestado pelos deuses (apékhthetai theoîsin/ apekhthómenos theoîsin; repare-se na repetição enfática).

O conjunto dessas menções nos levaria, assim, a supor uma combinação básica das iras de Posídon e o Sol contra o herói - por conta de atos narrados pelo próprio Odisseu nos Cantos 9 (cegamento do Ciclope) e 11 (morte do gado sagrado do Sol) -, cóleras essas que seriam por sua vez subsumidas e avalizadas pelo crivo superior de Zeus, sem o qual não poderiam ser de fato levadas a cabo.

Como os estudiosos já notaram, contudo, a dificuldade de Odisseu em retornar para casa parece operar com outro elemento complicador, além dos já citados: uma suposta cólera por parte da Atena, a deusa que, paradoxalmente, se dispõe a ajudar o herói na Odisseia. Lemos efetivamente no Canto 1 que a "horrenda volta" dos guerreiros de Troia - por ação da deusa - já se transformara em tema de canto: “Cantava o célebre aedo pra eles, que se sentavam/ em silêncio, ouvindo; a volta (nóston) de acaios ele cantava,/ horrenda (lugrón), que desde Troia lhes dera Palas Atena" (Od. 1, 325-327).

O sofrido retorno de Odisseu também teria origem num desfavor não especificado de Atena? Essa única alusão seria insuficiente para permitir que explorássemos esse motivo, mas o fato é que ele reaparece, de modo perturbador, nos Cantos 3 e 4 - onde acompanhamos outras experiências de navegação de volta para casa, após a guerra -, e ainda no Canto $5 . \mathrm{Na}$ narrativa de retorno de Nestor, somos informados da cisão do exército acaio, 
entre Menelau e Agamênon, no momento da partida (v. 130-200): em seu relato, o conflito inicialmente é visto como um plano de Zeus para que os argivos tivessem uma "volta horrenda" (lugròn nóston), já que nem todos eram "sensatos e justos" (noémones oudè dikaioi) na tropa (v. 132-134). Na sequência, a atribuição a Zeus permanece (“Zeus preparava sofrimento", v. 152, “Zeus ainda não queria a volta”, v. 160, e talvez em "o nume planejava males", v. 166), mas a ela vem se entrelaçar a notícia de que o mau destino de muitos se devia à "fúria destrutiva" (ménios ex oloês, v. 135) de Atena, de que havia uma "terrível cólera" (deinòn khólon, v. 145) da deusa que deveria ser aplacada. Com a referência ainda ao Treme-terra, que deveria ser propiciado (v. 178-179), vemos que a deusa vem efetivamente se juntar como elemento não desprezível - ao esquema já visto de atribuição de um retorno desfavorável.

$\mathrm{O}$ relato de Menelau, bem mais extenso, reforça o motivo da cólera divina em associação à volta da guerra, trazendo novamente Atena à baila. Antes, ele mesmo já havia indicado que é Zeus quem concede o retorno (v. 172-173) e que a presença de obstáculos deve ser vista - em relação especificamente a Odisseu - como fruto de uma irritação divina (agássesthai theòs autós,v. 182-183). Na descrição propriamente dita de suas aventuras (v. 349-352), ele menciona a sua retenção no Egito por falta de hecatombes (v. 351-360) e por "ofender os imortais" (athanátous alitésthai, v. 376-378); o atraso pela ausência de sacrifícios a Zeus e outros deuses (v. 472-474); e a necessidade de se reverter a cólera (khólon) divina (v. 583). A essas referências mais gerais, no entanto, vem se juntar um trecho decisivo, relativo à morte de Ájax Oilida, alvo não só da ira de Posídon - o que não nos surpreende, em se tratando de uma travessia marítima -, mas também de Atena (Od. 4, 499-511). 
Diante desses relatos, porém, que dado concreto teríamos a respeito de uma cólera de Atena dirigida contra seu protegido Odisseu? Com base em quê poderíamos integrá-la a esse esquema de perseguição que envolve Zeus, Posídon e o Sol? O paralelo com os outros retornos seria o bastante para suspeitar que o mesmo vale para o herói da Odisseia? Uma passagem que ainda não citamos parece ser decisiva; no momento em que Hermes chega à ilha de Calipso para determinar a soltura de Odisseu, ele diz à ninfa que os acaios, depois de saquearem Troia, "ofenderam" (alitonto) Atena, e esta então lhes mandou maus ventos e ondas (Od. 5, 105-111). Repare-se como ressurge aqui a mesma ideia empregada por Menelau - de que o atraso no retorno se liga ao ato de "ofender" (alitasthai) os deuses, como vimos (Od. 4, 376-378) -, com a diferença de que aqui está dito que a ofensa se dirige especificamente a Atena, e Odisseu está claramente implicado.

A partir disso, poderíamos considerar "a inescapável conclusão de que Odisseu está perdido porque não soube escapar da cólera de Atena", tal como coloca o problema George Dimock (1989, p. 40)? O próprio Dimock resolve a dificuldade propondo que Hermes estaria sugerindo uma versão tradicional do mito, mas que a resposta seguinte de Calipso, em que diz que Zeus estilhaçou a nau do herói (v. 130-134), nos mostraria que Homero não trabalha com essa versão na Odisseia (1989, 38-49 e 65). Para esse estudioso, portanto, essa discussão não deve ser levada adiante.

Outra estudiosa, no entanto, atribuiu a esse tópico um papel central, a ponto de figurar como título de seu trabalho sobre a Odisseia: trata-se do livro A cólera de Atena, de Jenny Clay, de 1983. Para ela, o tema da ira dessa divindade se desenvolve progressivamente nos cantos iniciais, ganhando destaque cada vez maior. Além dos passos elencados acima, Clay explora a ausência da deusa junto ao herói desde sua partida de Troia até o princípio do poema - ausência sentida pelos leitores/ouvintes entre os 
Cantos 9 a 12, e referida por três vezes -, chegando à conclusão de que a razão para o sumiço é, exatamente, a cólera de Atena ${ }^{5}$. Veja-se, por exemplo, o que ela diz sobre a fala de Hermes, citada acima:

A posição desses versos - imediatamente antes da primeira aparição de Odisseu na Odisseia - não poderia ser mais enfática ou significativa. A deusa que, a partir de agora, vai proteger e apoiar o herói, nem sempre se mostrou tão favorável. Sua presente benevolência deve ser entendida como a transformação de uma hostilidade anterior. (Clay, 1983, p. 46)

Em seguida, a estudiosa se pergunta qual seria a causa de tal ira (1983, p. 52). A resposta vem bem à frente, só no Capítulo 4. Clay lembra aí que os poemas do Ciclo Épico trabalhavam com esse motivo da cólera de Atena, e que vários episódios poderiam ter sido evocados por Homero para comprometer Odisseu, como o assassinato de Palamedes ou o roubo do Paládio. Ela propõe, contudo, que Homero não está interessado nas causas tradicionais e que devemos nos ater às evidências internas (1983, p. 187188). Analisando então o diálogo do Canto 13 entre Atena e o herói, onde vê uma alusão à ira da deusa (quando ele afirma que "um deus veio dispersar os acaios", v. 317), ela chega à conclusão de que Odisseu é o vencedor dessa disputa verbal, e que essa vitória, que ele, em seu "último triunfo", estaria espertamente apresentando como "aparente derrota" (1983, p. 201 e 208), é a chave para a compreensão do descontentamento divino:

É possível descobrir a causa da cólera de Atena dentro dos limites dessa cena. Em certo sentido, ela reencena a ofensa que originalmente

5 As referências surgem em $O d$. 13, 314-319 e 341-43, e $O d$. 6, 324-331; ver J. Clay (1983, p. 43-46).

Filosofia e Educação [RFE] - Volume 9, Número 1 - Campinas, SP

Fevereiro-Maio de 2017 - ISSN 1984-9605 - p. 25-44 
provocou a fúria. Para dizer de um modo simples, senão cru demais, Odisseu é esperto demais; sua inteligência gera um questionamento da superioridade dos próprios deuses. [...] A inteligência de Odisseu, sua mêtis, gera um questionamento da hierarquia fundamental entre deuses e homens e das fronteiras que os separam. Buscar romper esses limites que dividem homens e deuses pode levar ao heroísmo e sua recompensa, kléos áphthiton, "glória imperecível", mas certamente provoca a exposição a um grande perigo. (Clay, 1983, p. 209; grifo original)

Dessa maneira, Clay articula às cóleras mais explícitas do poema - de Posídon, do Sol e, como deus supremo, de Zeus - uma cólera "subterrânea" de Atena, que não precisa necessariamente se alinhar aos motivos tradicionais da perseguição da deusa a outros heróis. Ao mesmo tempo, a estudiosa fornece uma explicação para o fato de Atena não estar presente ao lado de Odisseu em suas aventuras, fato reconhecido tanto por ele quanto por ela no poema, e que intriga os estudiosos. Quanto à explicação para o fim da ira, Clay acredita que ela se associa não a uma possível transformação do herói em face dos seus sofrimentos, mas "à pressão dos acontecimentos em Ítaca" e à necessidade de "trazê-lo para casa para endireitar a situação" (1983, p. 234).

A leitura de Clay tem, a meu ver, dois problemas principais. Em primeiro lugar, ela dá destaque excessivo a uma suposta vitória de Odisseu no "embate" do Canto 13, quando a passagem parece indicar, ao contrário, que a afinidade entre o herói e a deusa está indelevelmente marcada pela superioridade desta em relação àquele: afinal, é Atena quem controla a situação, e Odisseu - apesar dos ardis - não é capaz de reconhecê-la. Sendo assim, não está indicada na cena nenhuma ameaça à soberania da deusa, como se o herói pudesse se alçar à mesma condição e sua astúcia ser alvo de

Filosofia e Educação [RFE] - Volume 9, Número 1 - Campinas, SP

Fevereiro-Maio de 2017 - ISSN 1984-9605 - p. 25-44 
uma recusa divina. Não há, em outros termos, nenhuma soberba humana assinalada, que pudesse resultar no surgimento de uma cólera imortal, nem uma justificativa apontada para o abandono dessa mesma cólera que vá na direção apontada pela norte-americana.

É verdade que, como a própria Clay defende na abertura do livro, com muita propriedade, não se deve simplesmente descartar uma leitura porque ela não está dita ou indicada, com todas as letras, no texto. A tarefa do intérprete consiste em organizar, num todo coerente e significativo, não só o que o poema diz, mas também (e sobretudo) o que ele deixa de dizer, o que vai implícito e pode ser inferido nas entrelinhas. A interpretação, em suma, é o resultado da soma entre o dito e o não-dito, soma sempre imprecisa e pessoal, na qual o literal tem que necessariamente se articular a um subtexto para ganhar sentido - tanto mais persuasivo quanto mais plausível parecer essa articulação. Portanto, a princípio não podemos negar validade à leitura de Clay, simplesmente porque Homero não afirma em momento algum que a causa da cólera de Atena consistia numa perigosa rivalidade de Odisseu. Aqui, contudo, devemos levantar o segundo entrave à sua interpretação: além de o poema não mostrar nem indicar nenhuma disputa do tipo como origem da ira e da ausência de Atena (a cena do Canto 13 é antes um momento de afirmação da impossibilidade de disputa), temos o fato de que a Odisseia aponta, claramente, a fúria de Posídon como motivo para o desaparecimento da deusa de junto do herói. Vejamos dois trechos do diálogo entre Odisseu e Atena. Primeiramente, ele contrapõe a sua dificuldade em reconhecer a presença da divindade a outro conhecimento, este inequívoco:

Mas isto eu mesmo bem sei: que antes me foste gentil (epie), enquanto em Troia lutávamos nós, os filhos dos acaios.

Filosofia e Educação [RFE] - Volume 9, Número 1 - Campinas, SP

Fevereiro-Maio de 2017 - ISSN 1984-9605 - p. 25-44 
Porém, depois de pilhar pólis íngreme de Príamo, embarcar nas naus e um deus (theós) vir dispersar os acaios, depois não te vi, menina de Zeus, nem te percebi pisando na minha nau, pra me tirar de uma dor...

(Od. 13, 314-319)

A explicação de Atena ocupa apenas três versos; repare-se no emprego da partícula grega toi (“o fato é que", na tradução), que tem valor inferencial, isto é, sugere a anuência do interlocutor:

Mas o fato é que (toi) eu não quis contra Posídon lutar, contra um irmão de meu pai que guardou rancor (kóton) por ti, colérico (khoómenos) por tu teres cegado o querido filho (Od. 13, 341-343).

É verdade que Clay vê exatamente nessa explicação a "fraqueza" de Atena e a chave para o entendimento da "vitória" de Odisseu: haveria aí uma grave inconsistência, uma vez que "o álibi da deusa abrange apenas o período posterior ao cegamento do Ciclope", não dando conta do período precedente, da partida de Troia até o incidente com Polifemo. Ligada a essa inconsistência, além do mais, viria se juntar uma mentira: a afirmação dela de que "sempre/ estou, em todos os sofrimentos, do teu lado, te guardando" (Od. 13, 300-301) teria sido posta a nu pelo próprio Odisseu na fala citada acima. A estudiosa, no entanto, recorre nesses momentos a um enfoque tipicamente analista - sempre em busca da lógica férrea do texto -, o que compromete suas conclusões ${ }^{6}$. Podemos afirmar, em resposta aos problemas colocados, que a fala de Atena sobre o apoio constante ao herói é válida e

6 Note-se como ela cita na p. 44, em tom de aprovação, o raciocínio infalível de W. Woodhouse, autor de The composition of Homer's Odyssey, de 1930.

Filosofia e Educação [RFE] - Volume 9, Número 1 - Campinas, SP

Fevereiro-Maio de 2017 - ISSN 1984-9605 - p. 25-44 
verdadeira, porque tem valor geral (não se chocando com o fato de a deusa ter ficado ausente por um período), e que o intervalo de tempo entre a partida de Troia e o episódio com o Ciclope é insignificante, não afetando a justificativa de Atena para seu sumiço. Buscar, aqui, uma cronologia exata e precisa parece ser contraproducente ${ }^{7}$.

Se ficarmos, no entanto, com o texto, e aceitarmos que a falta de atuação da deusa se liga a uma subordinação sua à cólera do tio compreensível dentro do esquema de respeito às prerrogativas e às áreas de atuação de cada divindade -, não teremos esclarecido a presença de uma suposta cólera sua contra Odisseu. Em outros palavras, teríamos a explicação para sua ausência, mas nenhuma indicação de sua ira. $\mathrm{O}$ poema, efetivamente, não explicita em momento algum um sentimento assim da deusa em relação ao herói, mas, em que pese a falta da indicação clara, é possível afirmar, diante do fato de ser Odisseu "o odiado" e de ser Atena tradicional perseguidora dos guerreiros que retornam, que indiretamente se estabelece um descontentamento da deusa como pano de fundo para grande parte das viagens do herói. Trata-se, assim, de uma ira latente, um desfavor silencioso, segundo o qual podemos deduzir que, não sendo a deusa "benévola", foi então "malévola", juntando-se a Zeus, Posídon e o Sol. Se não há na Odisseia, da parte do herói, qualquer ofensa a Atena, há contudo a indicação de uma tradição em que a cólera desempenha papel central: portanto, mesmo que Homero não jogue abertamente com ela, ficamos de todo modo com uma espécie de "contaminação" em relação a Odisseu, como se o fato de a deusa se submeter à cólera do tio representasse um apoio ou sanção a esse sentimento.

7 Para Paul Wathelet (1995, p. 180), que nos lembra também que Atena "está espantosamente ausente durante todo o périplo do filho de Laertes", tempo em que "Odisseu experimenta um número considerável de perigos, diante dos quais a ajuda da deusa teria sido bastante útil”, a desculpa dada aí é igualmente "pouco satisfatória".

Filosofia e Educação [RFE] - Volume 9, Número 1 - Campinas, SP

Fevereiro-Maio de 2017 - ISSN 1984-9605 - p. 25-44 
No que diz respeito especificamente à astúcia, há um outro ponto talvez ainda mais importante, na medida em que a ausência da deusa (e seu implicado desfavor) parecem representar um enfoque negativo dessa qualidade do herói, um mau funcionamento ou quase anulação de sua esperteza, o que faz com que as viagens do herói contrastem, de modo geral, com a segunda metade do poema, quando a divindade de "claros olhos" tem atuação fundamental junto ao protagonista. É verdade que ficamos muito próximos aqui de uma leitura alegórica, ao propormos que o sumiço de Atena equivale a um "sumiço" da astúcia de Odisseu, mas isso talvez seja inevitável, uma vez que nosso modo de leitura deriva, no final das contas, do mesmo racionalismo.

De qualquer maneira, o ponto que quero destacar aqui é bastante específico: parece-me que o "desaparecimento" indesejado a que fica sujeito Odisseu em suas aventuras - precisamente quando a deusa se ausenta - está associado a uma incapacidade de conseguir, por vontade própria, desaparecer. Ou seja: o movimento que é fundamental no homem astuto saber se ocultar sempre que assim desejar, como vemos na segunda metade da narrativa - dá lugar a uma ocultação involuntária, sobre a qual não tem controle, e que representa uma ameaça à existência e glória do herói "multiastuto". Odisseu é vítima de sua arma principal.

Esse Odisseu menos ou nada astuto, esquecido por Atena, odiado por Posídon com a anuência de Zeus, surge assim para nós como figura mais complexa e menos plana, associada a um Menelau, que ofende os deuses, a um Ájax Oilida, vítima de sua própria presunção, e aos acaios em geral, nem todos sensatos e justos. Nesse sentido, Clay parece estar no caminho certo ao atribuir certa soberba ao herói Odisseu, soberba que explicaria sua perseguição por uma cólera divina. Não estamos diante de um herói unívoco e modelar: assim como os soberbos pretendentes, alvos da fúria dos deuses 
(mênis theôn, Od. 2, 66), que com esses jovens se agastam (agassámenos, Od. 23,64), e assim como seus "atrevidos" companheiros, também Odisseu parece sofrer o que sofre por conta de uma transgressão moral ou atrevimento, ainda que esta não seja jamais explicitada, ficando apenas sugerida - um efeito difuso produzido pelo poema, que ajuda a tornar assim mais denso um personagem que, do contrário, seria apenas exemplo de conduta.

Seja como for, temos que reconhecer que tanto para Odisseu quanto para nós, leitores/ouvintes, a articulação entre os motivos divinos permanece sempre sinuosa, resistente a um esclarecimento total. $\mathrm{O}$ que tentamos ressaltar aqui, contudo, é que Odisseu, sendo "o odiado", associa-se a um motivo fundamental - da cólera divina -, e que esse motivo, sendo ativado na narrativa por meio de outros retornos e de toda uma tradição que vai aludida, não só implica a figura de Atena, mas também a abordagem da qualidade principal desse herói e uma problematização do seu comportamento, do ponto de vista ético. Se é fato que a narrativa não se posiciona abertamente a esse respeito, ainda assim pode-se propor que essa estratégia tem precisamente o efeito não de inocentar Odisseu ou livrá-lo de qualquer questionamento, mas, antes, de dar ao herói um tratamento mais oblíquo e rico, que ressoa mesmo nos versos finais do poema, quando Atena lhe diz: "Laercida divogênito, multiengenhoso Odisseu:/ abstém-te, e cessa a disputa da guerra niveladora,/ pra nunca o Cronida, Zeus amplividente, ter cólera (kekholósetai)". (Od. 24, 542-544) ${ }^{8}$

Como isso tudo de encaixa no conjunto do poema? Através de seu personagem central, que lição a Odisseia passava aos antigos e pode passar

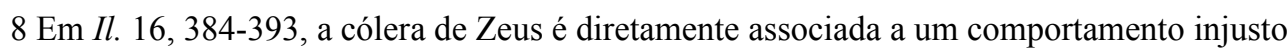
dos homens. Sobre esses versos finais da Odisseia, ver C. Segal $(1994,226)$.

Filosofia e Educação [RFE] - Volume 9, Número 1 - Campinas, SP

Fevereiro-Maio de 2017 - ISSN 1984-9605 - p. 25-44 
ainda hoje a nós - se Homero era de fato o "educador da Grécia", como nos diz Platão na República (606c)? Há algumas respostas possíveis, e aqui, à guisa de conclusão, quero destacar duas. A primeira delas diz respeito à ideia de que a vida humana pode ser marcada pela predestinação, ou seja, de que pode haver para cada um de nós um fato, um sentimento, uma pessoa, um nome, que organizam de modo inescapável nosso futuro. A realização desse futuro, por outro lado, só pode se dar por meio da participação ativa daquele sobre o qual recai, e portanto a ideia de predestinação, se vista com a devida atenção, não exclui a ação humana - antes a exige para sua consecução. Odisseu nasceu, como vimos, com a marca do ódio pendendo sobre si, mas a presença concreta desse ódio - de que acaba sendo, efetivamente, vítima - é fruto de seus próprios atos, o que impede, é bom destacar, que mesmo como vítima ele possa empregar o discurso da "vitimização". Em outras palavras, esse poema grego quer pintar não um homem à mercê da fatalidade, que deve simplesmente aceitá-la pacientemente, mas antes alguém que, apesar de sentir sobre si a marca de um poder maior, tem total capacidade e vontade de agir com e sobre ele.

Uma segunda lição está associada ao comportamento heroico. Num mundo (como é o homérico) apresentado sempre em dois planos - o divino e o mortal -, a reação violenta de um deus tem o propósito de marcar claramente a fronteira que distingue esses dois tipos de seres, ou sublinhar, por contraste, a precariedade do humano frente à perenidade do sobrehumano. No horizonte do pensamento da Grécia Antiga, essa cólera divina é efetivamente justa, porque está sempre a reatualizar os limites dentro dos quais deuses e homens devem viver: a ação excessiva do herói exige a reação vingativa. E aqui é importante lembrar que o termo grego dike, que traduzimos por "justiça", tem também o sentido, em Homero, de “comportamento normal”, “modo habitual de ser”. Mais do que uma justiça 
“legal”, inscrita em códigos, o que vem apresentado, portanto, é uma justiça "cósmica", que baliza os comportamentos de homens e deuses.

Somados, esses dois aspectos - ou duas lições - formariam a base de uma "filosofia" da Odisseia, filosofia formulada de modo indireto e oblíquo, e que admite os mais variados desdobramentos. A meu ver, ela se torna ainda mais complexa pelo fato de o personagem central do poema aparecer, como se sabe, em grande parte do tempo disfarçado de mendigo: é como se Homero quisesse nos chamar a atenção, como um "proto-Sócrates", para o fato de que, na formulação verdadeiramente filosófica, a dedicação ao jogo entre aparência e essência é sempre o exercício mais importante.

\section{Referências}

CLAY, J. The wrath of Athena: gods and men in the Odyssey. Princeton: Princeton University Press, 1983.

DE JONG, I. A narratological commentary on the Odyssey. Cambridge: Cambridge University Press, 2001.

DI BENEDETTO, V. Omero: Odissea. Milano: BUR, 2010.

DIMOCK, G. The unity of the Odyssey. Amherst: The University of Massachusetts Press, 1989.

MERRY, W.; RIDDELL, J. Homer's Odyssey. V. 1 (Books I-XII). Oxford: The Clarendon Press, 1876.

MONRO, D. Homer's Odyssey. V. 2. (Books XIII-XXIV). Oxford: The Clarendon Press, 1901.

PERADOTTO, J. Man in the middle voice: name and narration in the Odyssey. Princeton: Princeton University Press, 1990.

SEGAL, C. Singers, heroes, and gods in the Odyssey. Ithaca: Cornell University Press, 1994.

STANFORD, W. The Odyssey of Homer. 2 v. London: St. Martin Press, 1947.

Filosofia e Educação [RFE] - Volume 9, Número 1 - Campinas, SP

Fevereiro-Maio de 2017 - ISSN 1984-9605 - p. 25-44 
, The Homeric etymology of the name Odysseus, Classical philology 47 (1952): 209-213.

WATHELET, P. Athéna chez Homère ou le triomphe de la déesse, Kernos 8 (1995): 167-195.

WOODHOUSE, W. The composition of Homer's Odyssey. Oxford: The Clarendon Press, 1930. 